\title{
OPTIMAL SOLUTIONS FOR INVERSE STRUCTURAL MODELS OF BIMOBILE SySTEMS
}

\author{
Comanescu, A.; Comanescu, D.; Dugaesescu, I., \& \\ UNGUREANU, L.M.
}

Abstract: The inverse structure modeling of bi mobile mechanisms is based on the passive modular groups mentioned in the classical theory of mechanisms (Crossley, 1968; Pelecudi 1967). In function of the number of links and independent contours the inverse models may have a maximum number of links for their passive groups. Having in view the inverse models and the complex passive groups with a higher number of links and loops in the paper optimal solutions for bi mobile mechanisms is presented. Such bi mobile mechanisms applied to mechanical structures for robot arms and legs for mobile platforms ensure a higher functional precision.

Key words: Bi-mobile mechanism, robot arm, robot leg, Baranov truss, inverse model
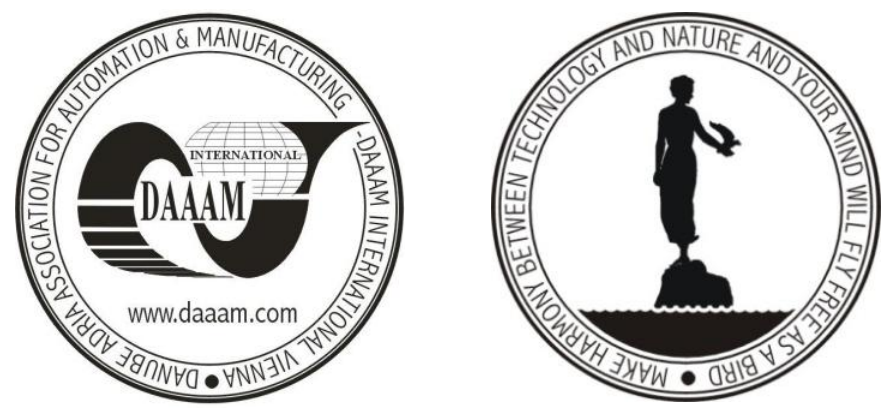

Authors' data: Univ.Prof. Dipl.-Ing. Dr.techn. Comanescu, A[driana]; Univ.Prof. Dipl.-Ing. Dr.techn. Comanescu, D[inu]; Lect.Dr.-Ing. Dugaesescu, I[leana]; Asist.Dr.-Ing. Ungureanu, L[iviu], Mechanisms and Robots Theory Department, Faculty of Engineering and Management of Technological Systems, University Politehnica of Bucharest, Splaiul Independentei 313, 060042, Bucharest, Romania,adrianacomanescu@gmail.com,dinucomanescu@yahoo.com, ileana_d1@yahoo.com, ungureanu.liviu.marian@gmail.com

This Publication has to be referred as: Comanescu, $\mathrm{A}$ [driana]; Comanescu, $\mathrm{D}$ [inu]; Dugaesescu, I[leana] \& Ungureanu, L[iviu] (2014). Optimal Solutions for Inverse Structural Models of Bimobile Systems, Chapter 31 in DAAAM International Scientific Book 2014, pp.383-400, B. Katalinic (Ed.), Published by DAAAM International, ISBN 978-3-901509-98-8, ISSN 1726-9687, Vienna, Austria DOI: $10.2507 /$ daaam.scibook.2014.31 


\section{Introduction}

The paper, the result of many years of research is a synthesis of the past and present, future structural theory in the mechanisms science.

In the last part of the $20^{\text {th }}$ century the mechanisms with two degrees of mobility become especially usefully for various systems in robotics and other equipment (Angeles, 2003). In the same time two concepts - direct and inverse models were developed (Voinea et al., 2000). For the direct model the parameters of any link and pair are principally expressed by those of the active pairs. For the inverse model the active pairs (actuators) parameters are determined relative to the effector parameters.

The effector extremity of such mechanisms may describe any curve in the certain domain of the mechanism.

The inverse structure modeling of bi mobile mechanisms is based on the passive modular groups mentioned in the classical theory of mechanisms (Artobolevski, 1977; Crossley, 1968; Manolescu et all., 1972; Pelecudi 1967).

In order to design structures for bi-mobile mechanisms the following steps are mentioned (Comanescu et al., 2010):

- to put into evidence the matrix of possible bases and effectors for the linkages;

- to eliminate the non-distinct solutions due to the symmetrical characteristics of the linkages;

- to verify the solutions for bases and effectors through the inverse structural model characterized by a zero instantaneous degree of mobility;

- the selection of the optimum structural-constructive solutions including a minimum number of passive modular groups;

- to place in the mechanism structure the active kinematic pairs (actuators);

- to create an optimal structural solution with a minimum number of modular groups.

A bi-mobile planar mechanism with an optimal structure used either for a robot arm or for a leg of a walking robot (Kakudou et al., 2013) must contain a minimum number of modular passive groups for its inverse model and also a minimum number of modular groups for the direct model.

\section{Structural considerations}

By using the 40 linkages with three independent loops and five degrees of freedom (Tab. 1) the bi-mobile planar mechanisms may be obtained when somebody nominates the basis and the effector. All these structural solutions have nine links, eleven lower pairs and three independent loops.

The mobility instantaneously becomes zero due to the placing a connection between the basis and the extremity of the effector and the inverse model has zero degree of mobility. This connection is equivalent to a lower pair with two constrains and a single mobility. 
By excluding its basis the structure is composed by an even number of links, which determine passive modular groups [Comanescu et al., 2010].

The planar structures with zero degree of mobility are mentioned [Manolescu et al., 1972) and named Baranov trusses. Any structure with zero degree of mobility has an odd number of links. In the literature [Artobolevski, 1977; Manolescu, 1972] there are mentioned the passive modular groups with 2, 4 and 6 elements.

In the case of the previously mentioned linkages (Tab. 1) the inverse models are constituted by the following passive modular groups with $2+2+2+2,2+4+2,2+2+4$, $4+2+2,2+6,6+2$ or 8 elements.

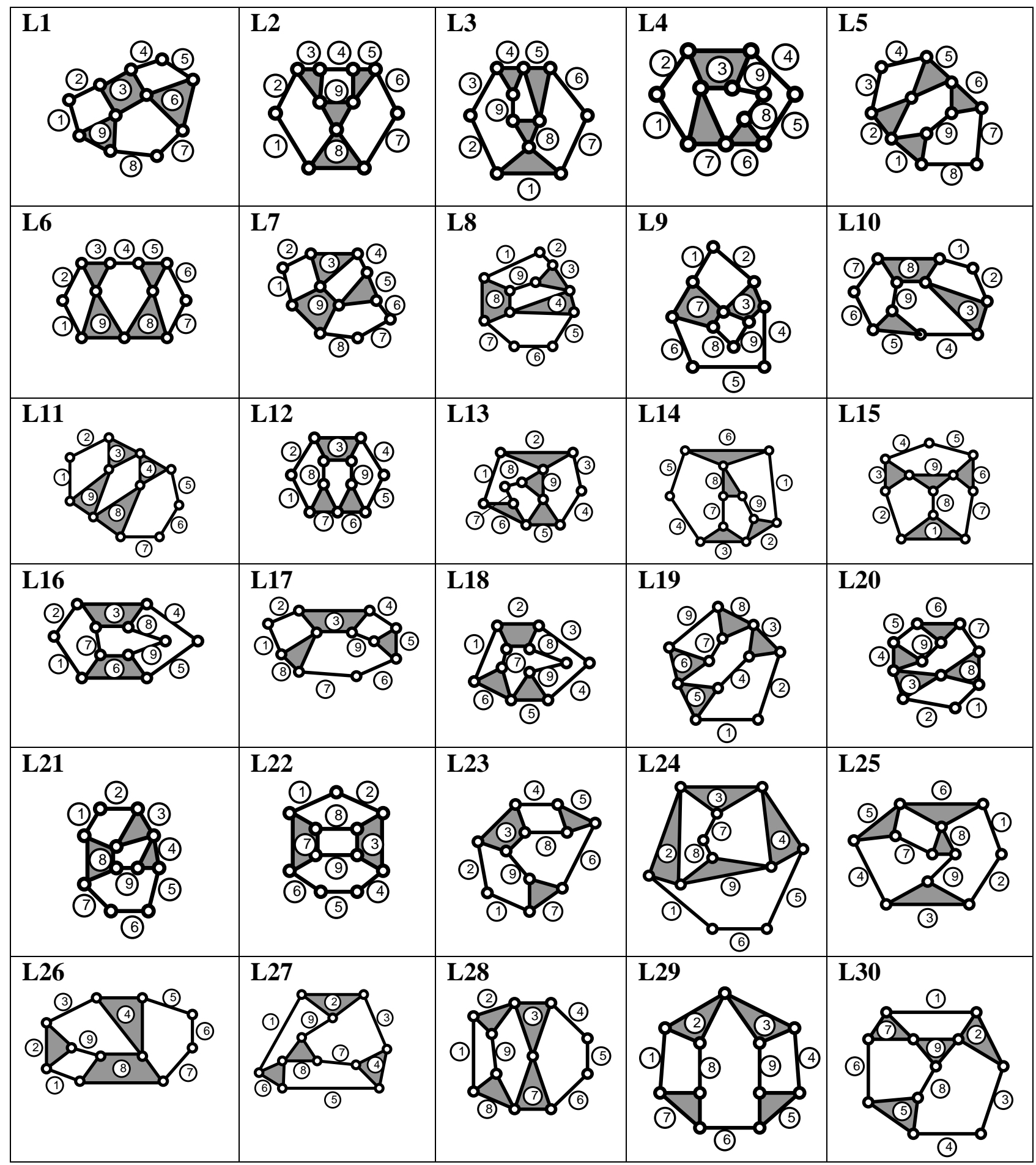


Comanescu, A.; Comanescu, D.; Dugaesescu, I. \& Ungureanu, L.: Optimal Solutio...

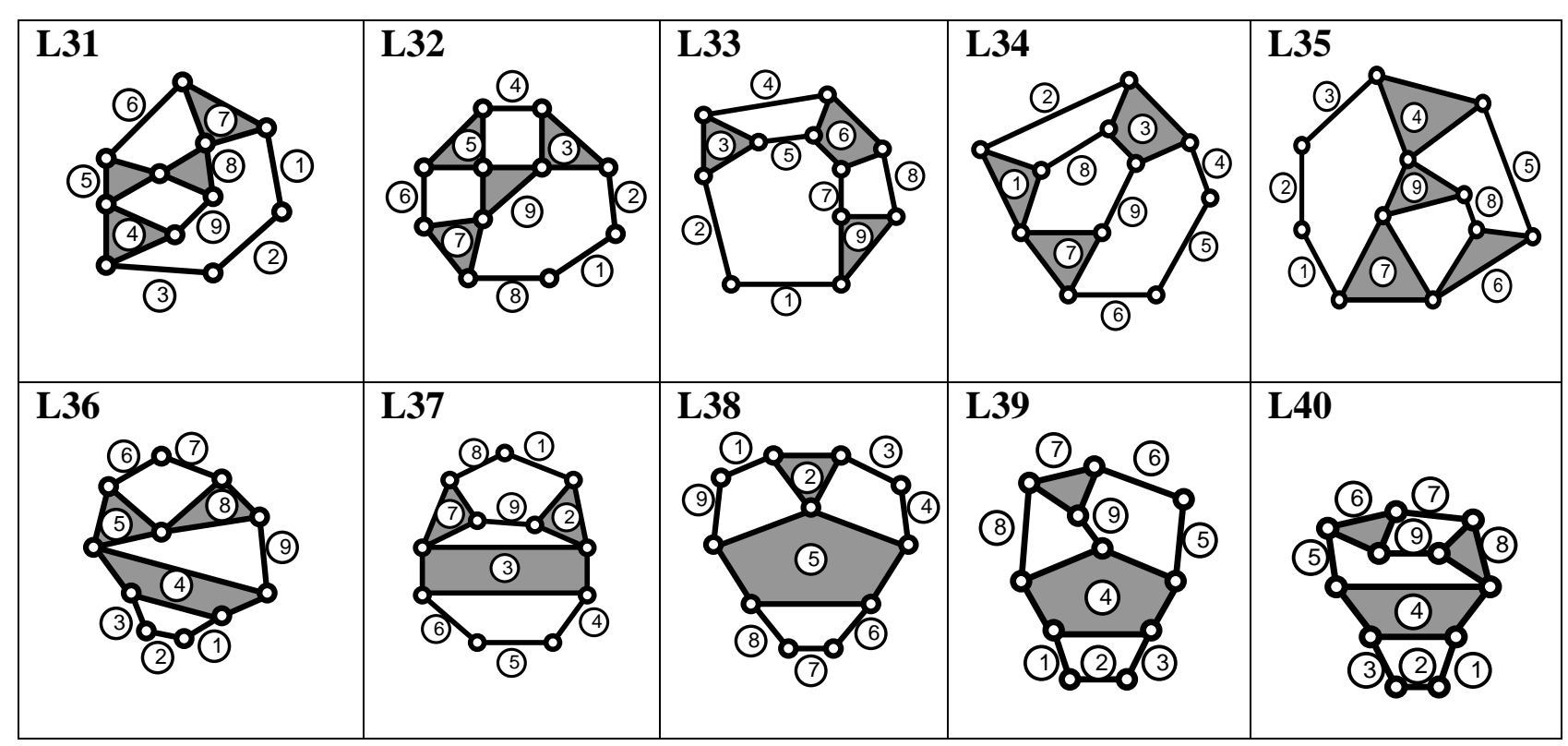

Tab. 1. Three loops planar linkages with five degrees of freedom

The optimal solutions have only one passive modular group with 8 elements connected at the adopted basis. Such groups with 8 elements may be obtained from Baranov trusses with nine elements and four independent loops [Tab. 2] by eliminating a link.

The BT1-BT5 Baranov trusses [Comanescu et al., 2010] have respectively 3, 5 and 7 elements and 1,2 and 3 independent loops and are eliminated in Tab. 1.

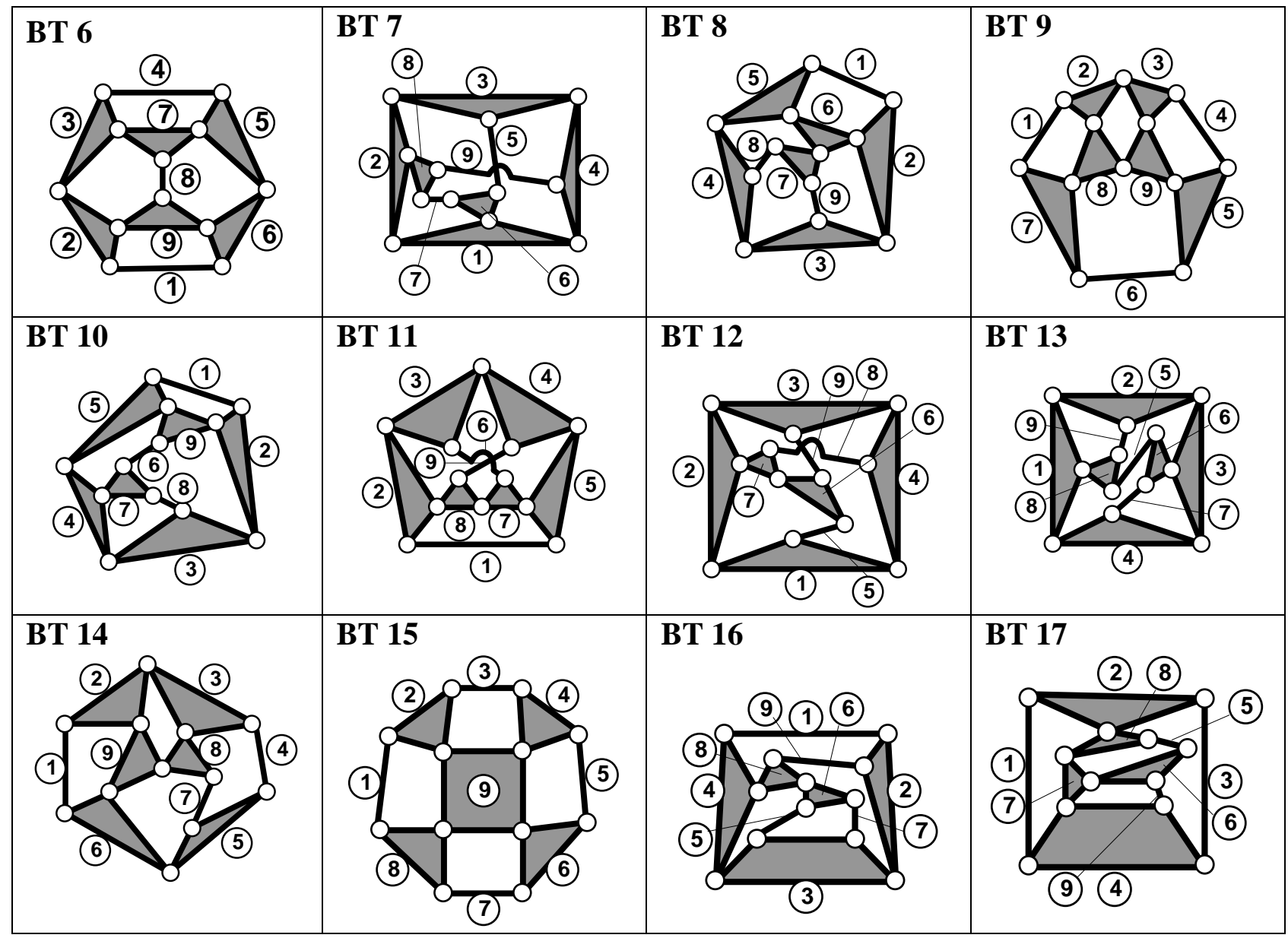




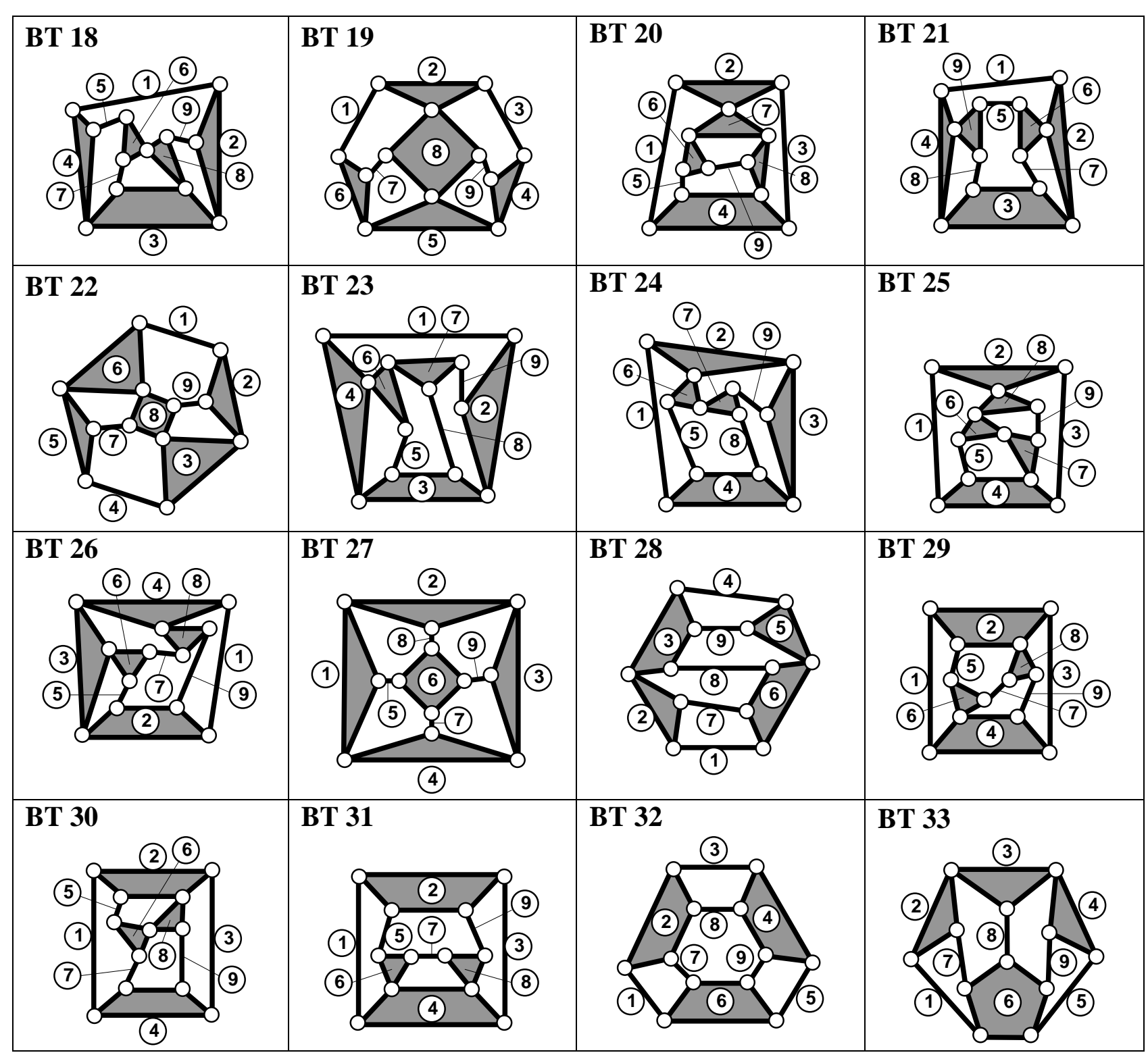

Tab. 2. Baranov trusses with nine elements and four loops

\section{Optimal solutions for the inverse models}

In some researches of many years there are analyzed the matrix of possible bases and effectors for the linkages mentioned in Tab. 1.

$A=\left[\begin{array}{ccccccccc}0 & A[1,2] & A[1,3] & A[1,4] & A[1,5] & A[1,6] & A[1,7] & A[1,8] & A[1,9] \\ A[2,1] & 0 & A[2,3] & A[2,4] & A[2,5] & A[2,6] & A[2,7] & A[2,8] & A[2,9] \\ A[3,1] & A[3,2] & 0 & A[3,4] & A[3,5] & A[3,6] & A[3,7] & A[3,8] & A[3,9] \\ A[4,1] & A[4,2] & A[4,3] & 0 & A[4,5] & A[4,6] & A[4,7] & A[4,8] & A[4,9] \\ A[5,1] & A[5,2] & A[5,3] & A[5,4] & 0 & A[5,6] & A[5,7] & A[5,8] & A[5,9] \\ A[6,1] & A[6,2] & A[6,3] & A[6,4] & A[6,5] & 0 & A[6,7] & A[6,8] & A[6,9] \\ A[7,1] & A[7,2] & A[7,3] & A[7,4] & A[7,5] & A[7,6] & 0 & A[7,8] & A[7,9] \\ A[8,1] & A[8,2] & A[8,3] & A[8,4] & A[8,5] & A[8,6] & A[8,7] & 0 & A[8,9] \\ A[9,1] & A[9,2] & A[9,3] & A[9,4] & A[9,5] & A[9,6] & A[9,7] & A[9,8] & 0\end{array}\right]$

The matrix is a symmetrical one, so that $A[i, j]=A[j, i]$ and $A[i, i]=0$. 
Comanescu, A.; Comanescu, D.; Dugaesescu, I. \& Ungureanu, L.: Optimal Solutio...

$\mathrm{A}[\mathrm{i}, \mathrm{j}]$ includes the $\mathrm{i}$ basis and the $\mathrm{j}$ effector adopted for the linkage.

There are also verified all solutions for each linkage bases and effectors through the inverse structural model characterized by a zero instantaneous degree of mobility.

In the next tables at the top $A[i, j]$ is given. The linkage with the $i$ basis and the $j$ effector is mentioned at the top and below of each linkage the Baranov truss corresponding for its inverse model is also included. One may note that the Baranov truss is the same when the basis is changed with the effector.

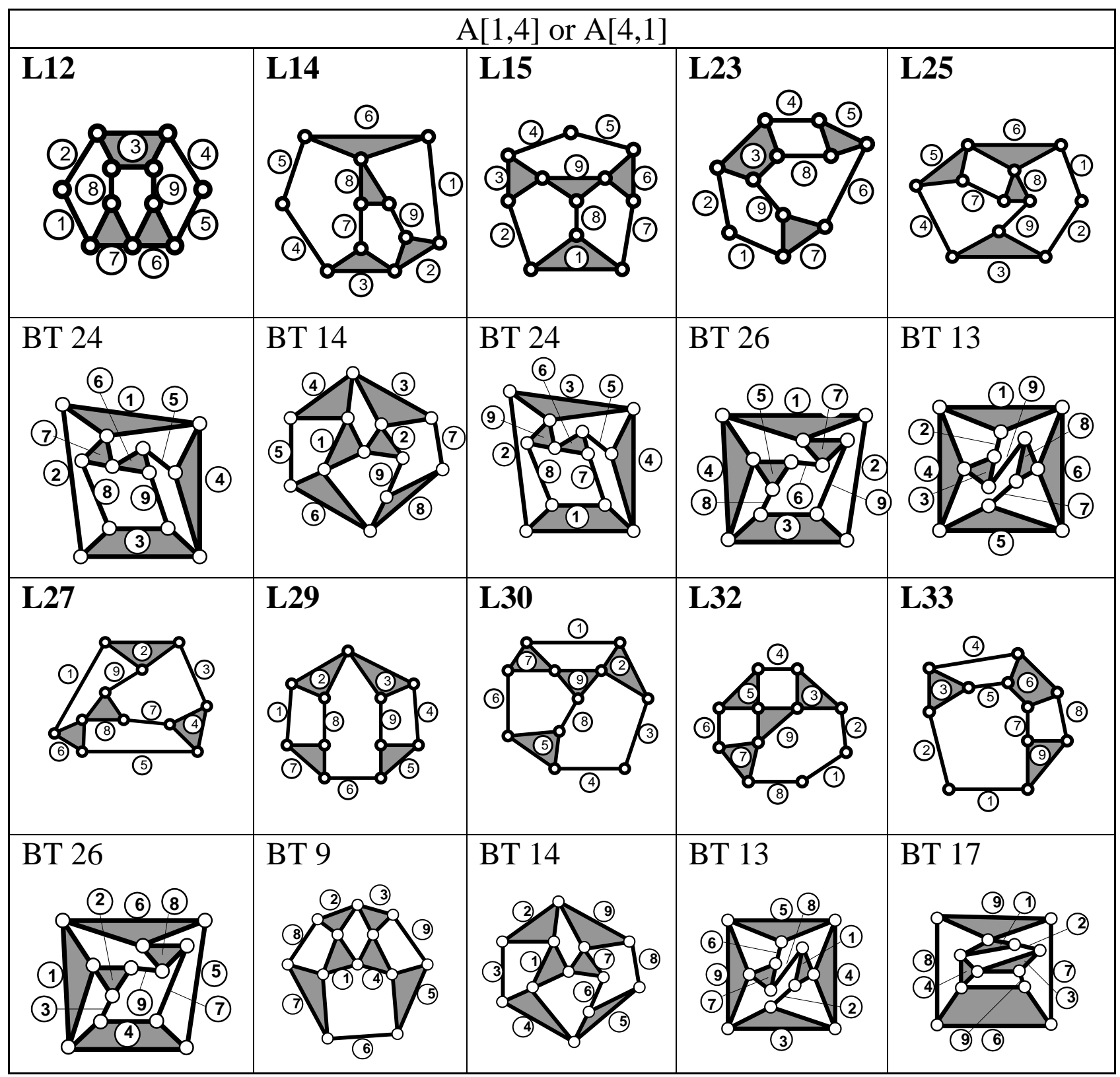

Tab. 3. The inverse models for linkages with 1 basis and 4 effector or 4 basis and 1 effector

In the Tab. 3 there are mentioned 19 solutions due to the fact that the L29 linkage has a symmetrical structure relative to the 1 and 4 links.

When the basis is the link 1 and the effector is the link 5 or vice versa the solutions of the inverse models of the linkages are presented in the Tab. 4. There are found 17 distinct solutions, because the L12 linkage has a symmetrical structure. 


L12

Tab. 4. The inverse models for linkages with the 1 basis and the 5 effector or the 5 basis and the 1 effector

In the Tab. 5 there are given the inverse models for the linkages (Tab. 1) when the basis is the link 1 and the link 6 is the effector or vice versa. The total distinct solutions are 18 ones. 
Comanescu, A.; Comanescu, D.; Dugaesescu, I. \& Ungureanu, L.: Optimal Solutio...

L2

Tab. 5. The inverse models for linkages with the 1 basis and the 6 effector or the 6 basis and the 1 effector 
When the 1 basis and the 7 effector and vice versa are adopted, the results are presented in the Tab. 6 .

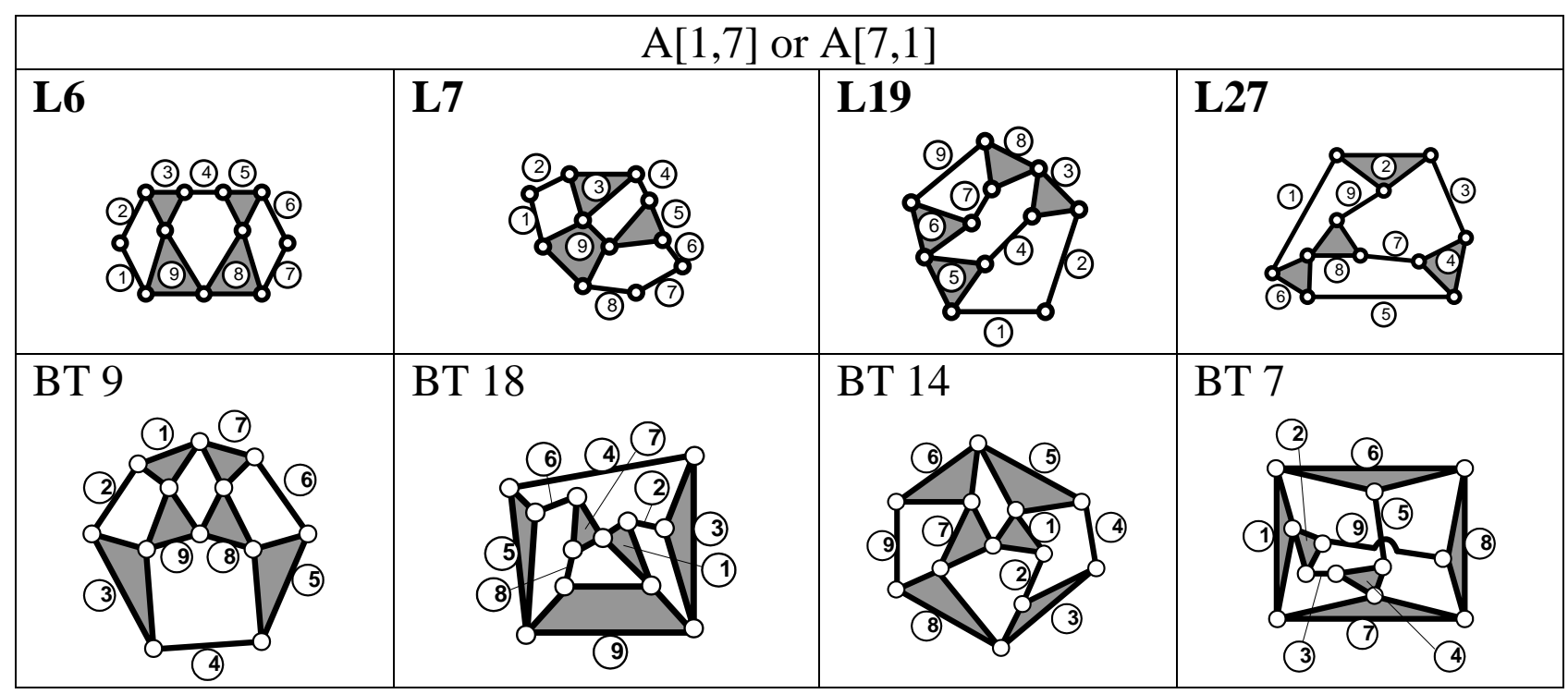

Tab. 6. The inverse models for the 1 basis and the 7 basis or vice versa

Due to the symmetry of the L6 and L27 linkages in the Tab. 6 one may only find 6 distinct solutions.

The solutions for the 1 basis and the 8 or 9 effectors are respectively presented in the Tab. 7 and 8, which of them having two distinct solutions for inverse models.

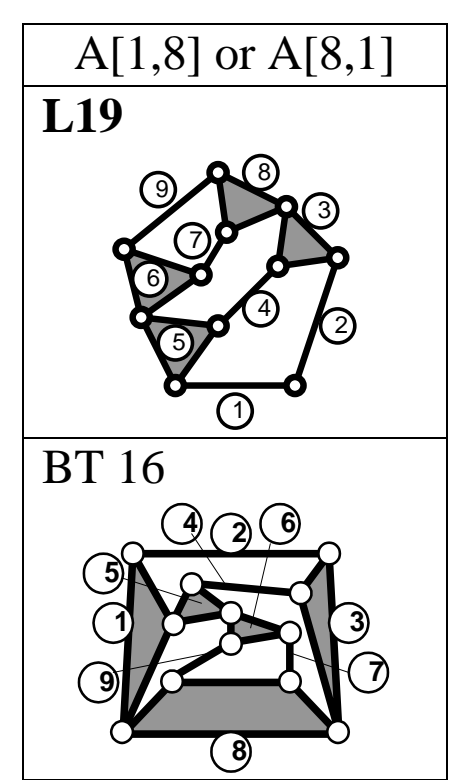

Tab. 7. Solutions for the 1 or 8 basis and the 8 or 1 effector

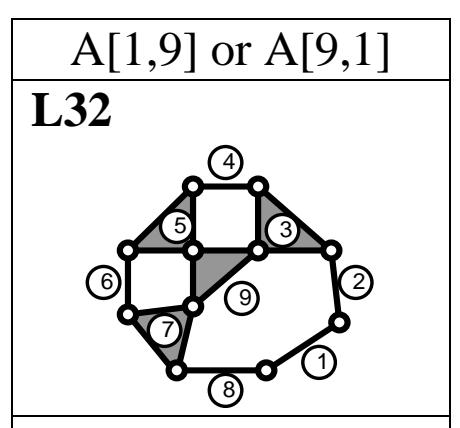

BT 15

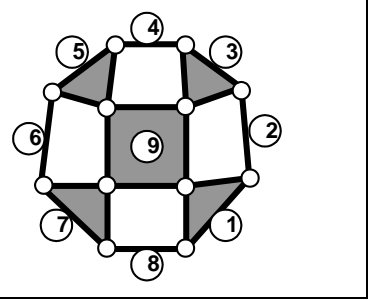

The solutions for the 2 or 5 and 6 links as a basis and the 5 or 6 and 2 links as an effector are presented in the Tab. 9 and Tab. 10.

In the Tab. 9 there are given 16 distinct solutions and similarly in the Tab. 10 there are found 29 distinct solutions the L6 linkage being a symmetrical one. 


\section{$\mathrm{A}[2,5]$ or $\mathrm{A}[5,2]$}

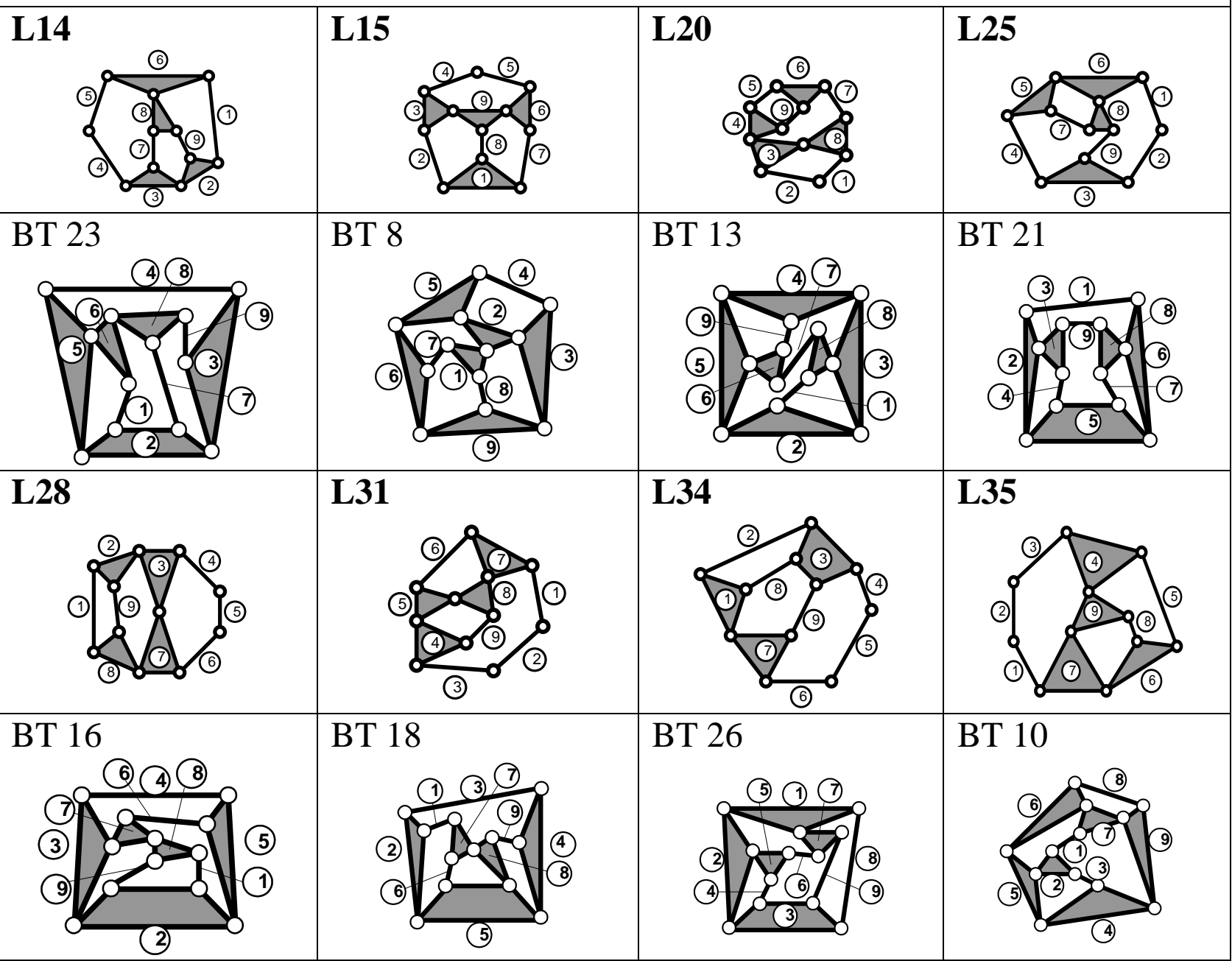

Tab. 9. Solutions for the 2 or 5 basis and the 5 or 2 effector

$\mathrm{A}[2,6]$ or $\mathrm{A}[6,2]$

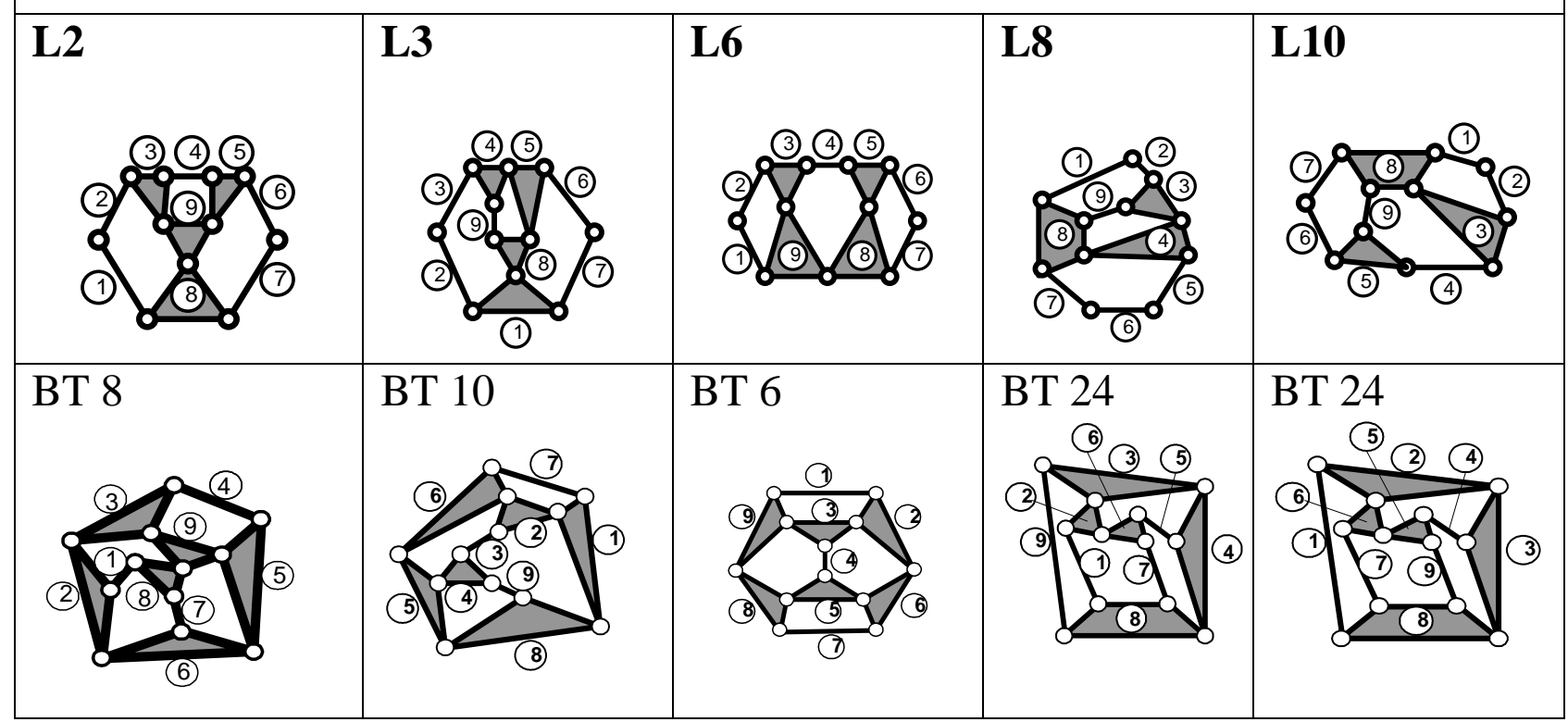




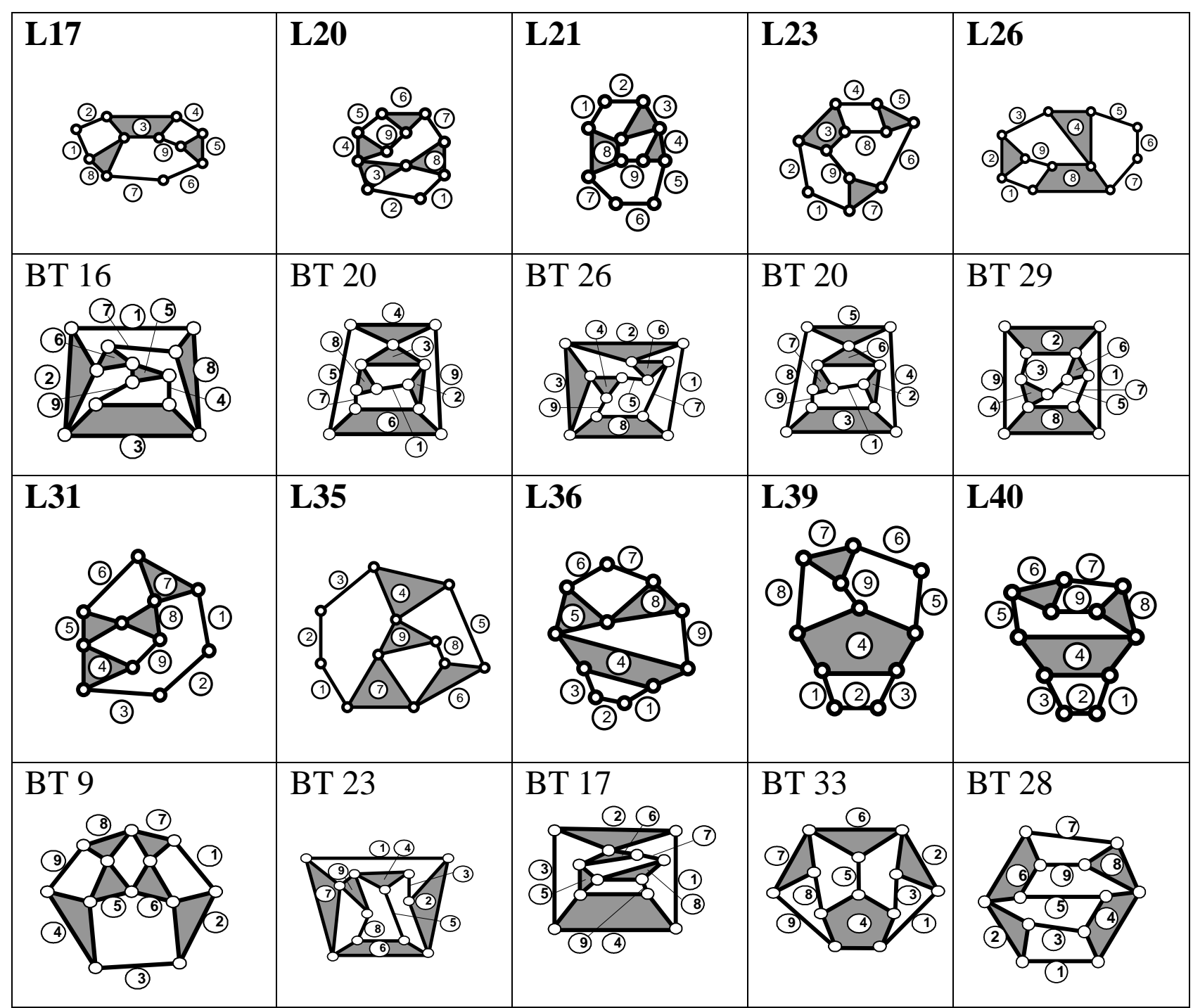

Tab. 10. The solutions for the 2 or 6 basis and the 6 or 2 effector

The inverse models for linkages when the basis is the 2 link and the effector is the 7 link or vice versa is also presented in the Tab. 11. There are shown eight distinct solutions.

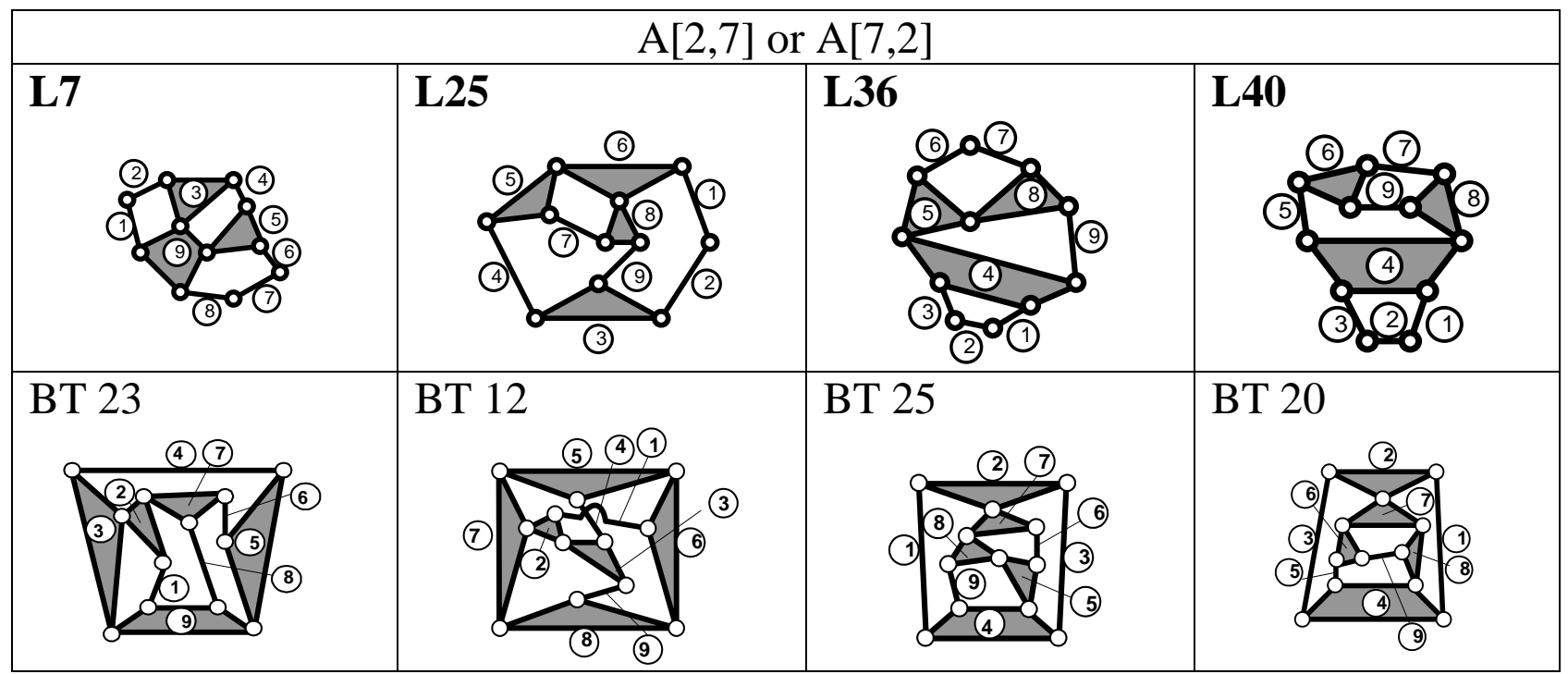

Tab. 11. The solutions for the 2 or 7 basis and the 7 or 2 effector 
Comanescu, A.; Comanescu, D.; Dugaesescu, I. \& Ungureanu, L.: Optimal Solutio...

In the Tables 12, 13 there are given similar solutions, that is two for each table.

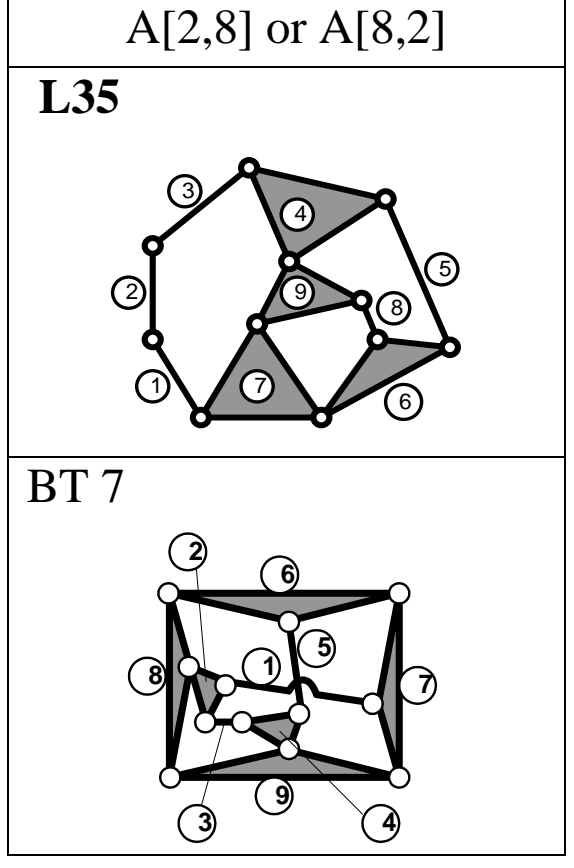

Tab. 12. Solutions for the 2 or 8 basis and the 8 or 2 effector

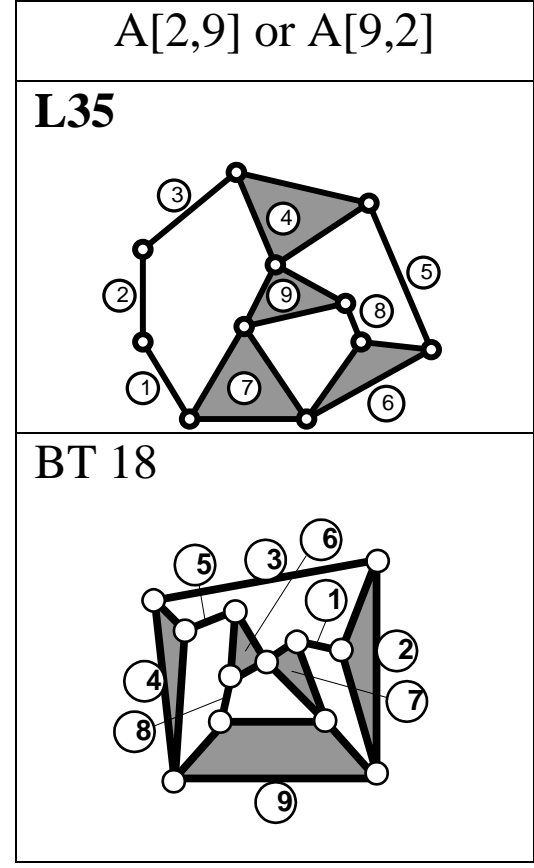

Tab. 13. Solutions for the 2 or 9 basis and the 9 or 2 effector

By changing the basis with the 3 link and the effector with the 6 link the new solutions are given in the Tab. 14. Totally one may find eight solutions.

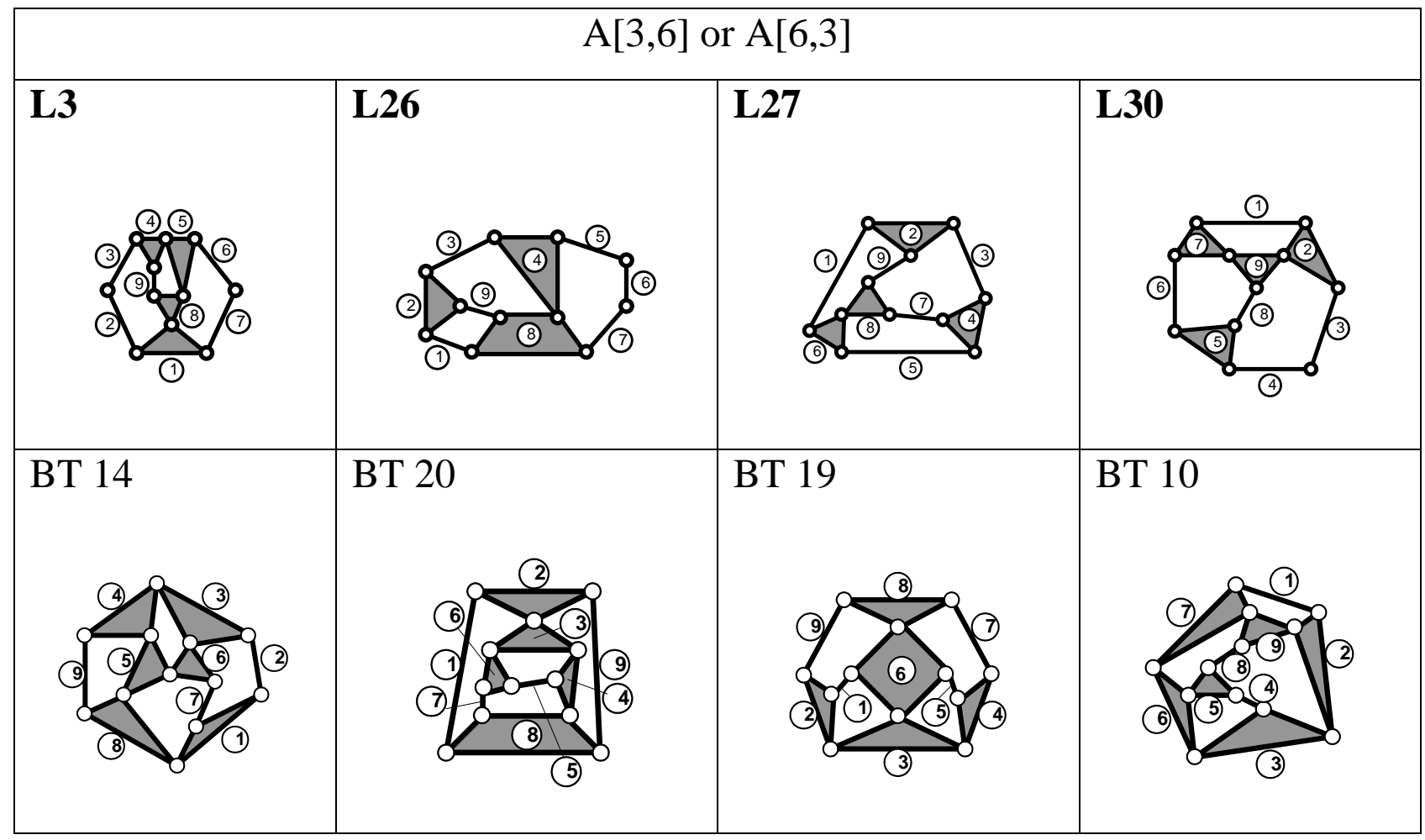

Tab. 14. Solutions for the 3 or 6 basis and the 6 or 3 effector 
In the next tables there are given the other inverse models solutions for linkages with three independent loops according to the basis - effector matrix (1).

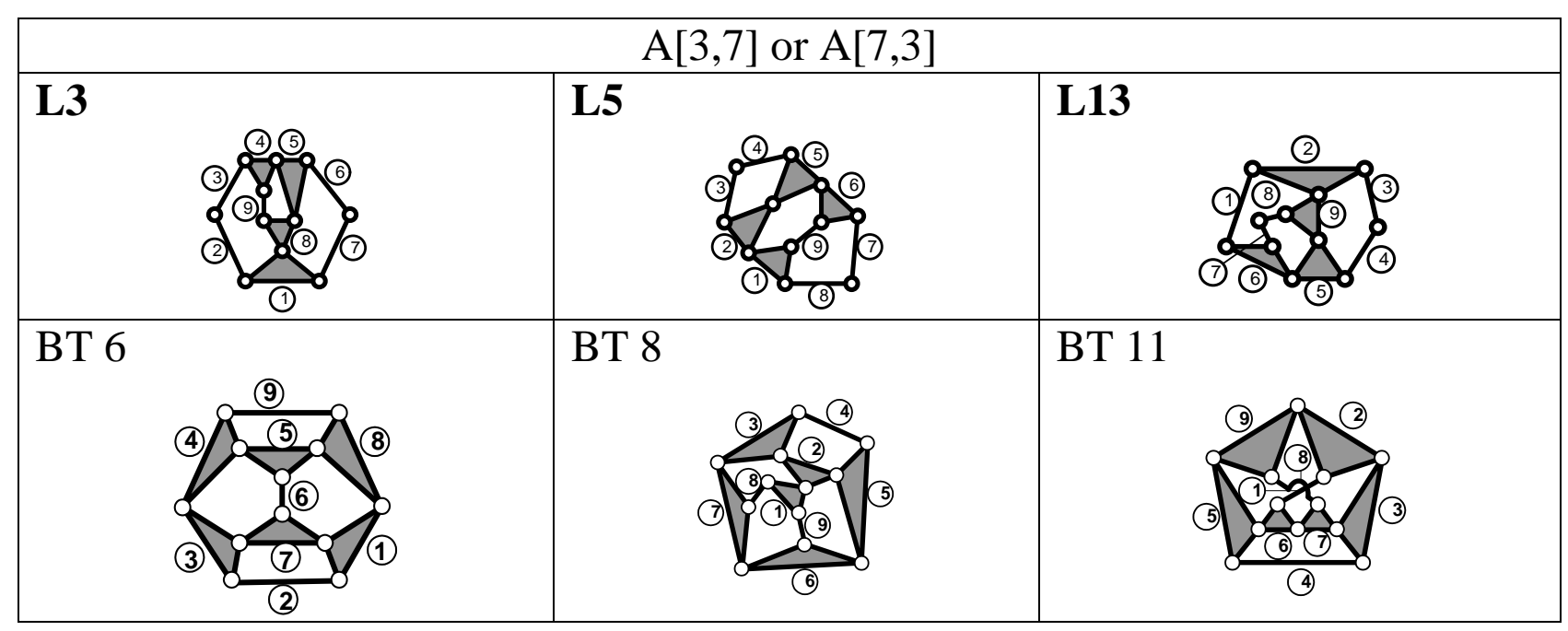

Tab. 15. Solutions for the 3 or 7 basis and the 7 or 3 effector

\begin{tabular}{|l|l|l|l|}
\hline L5 & L13 \\
\hline & & \\
\hline
\end{tabular}

Tab. 16. Solutions for the 3 or 8 basis and the 8 or 3 effector

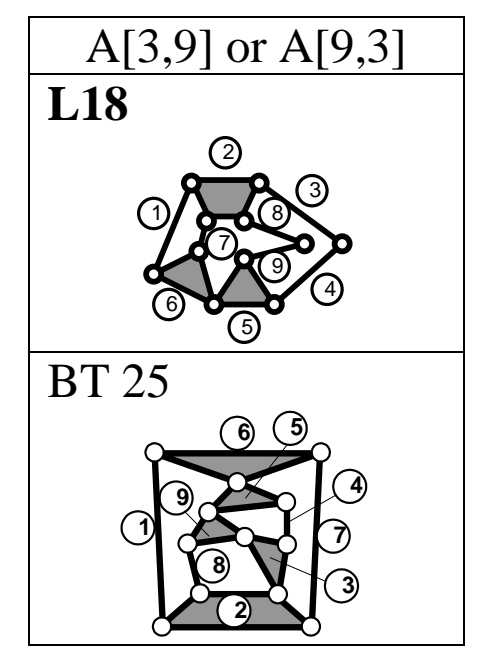

Tab. 17. Solutions for the 3 or 9 basis and the 9 or 3 effector

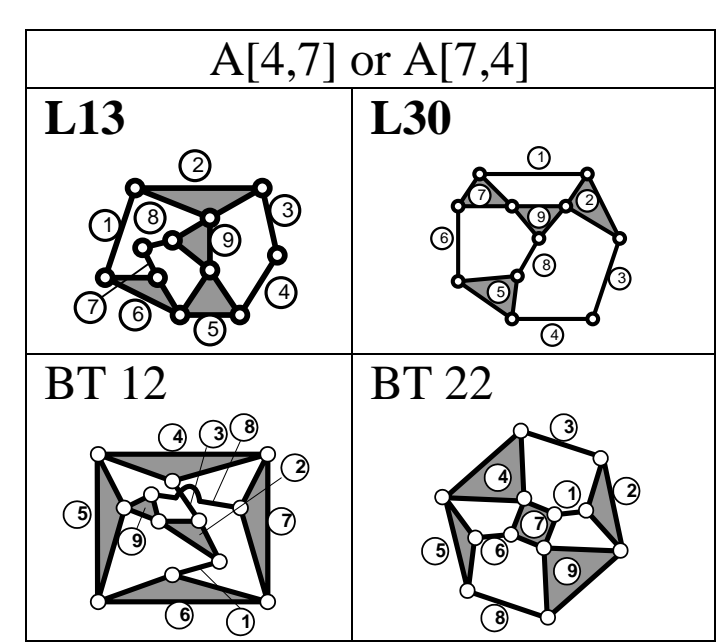

Tab. 18. Solutions for the 4 or 7 basis and the 7 or 4 effector 
Comanescu, A.; Comanescu, D.; Dugaesescu, I. \& Ungureanu, L.: Optimal Solutio...

\begin{tabular}{|l|l|l|}
\hline \multicolumn{2}{|c|}{$\mathrm{A}[4,8]$ or $\mathrm{A}[8,4]$} & L15 \\
\hline L13 & L14 \\
\hline
\end{tabular}

Tab. 19. Solutions for the 4 or 8 basis and the 8 or 4 effector

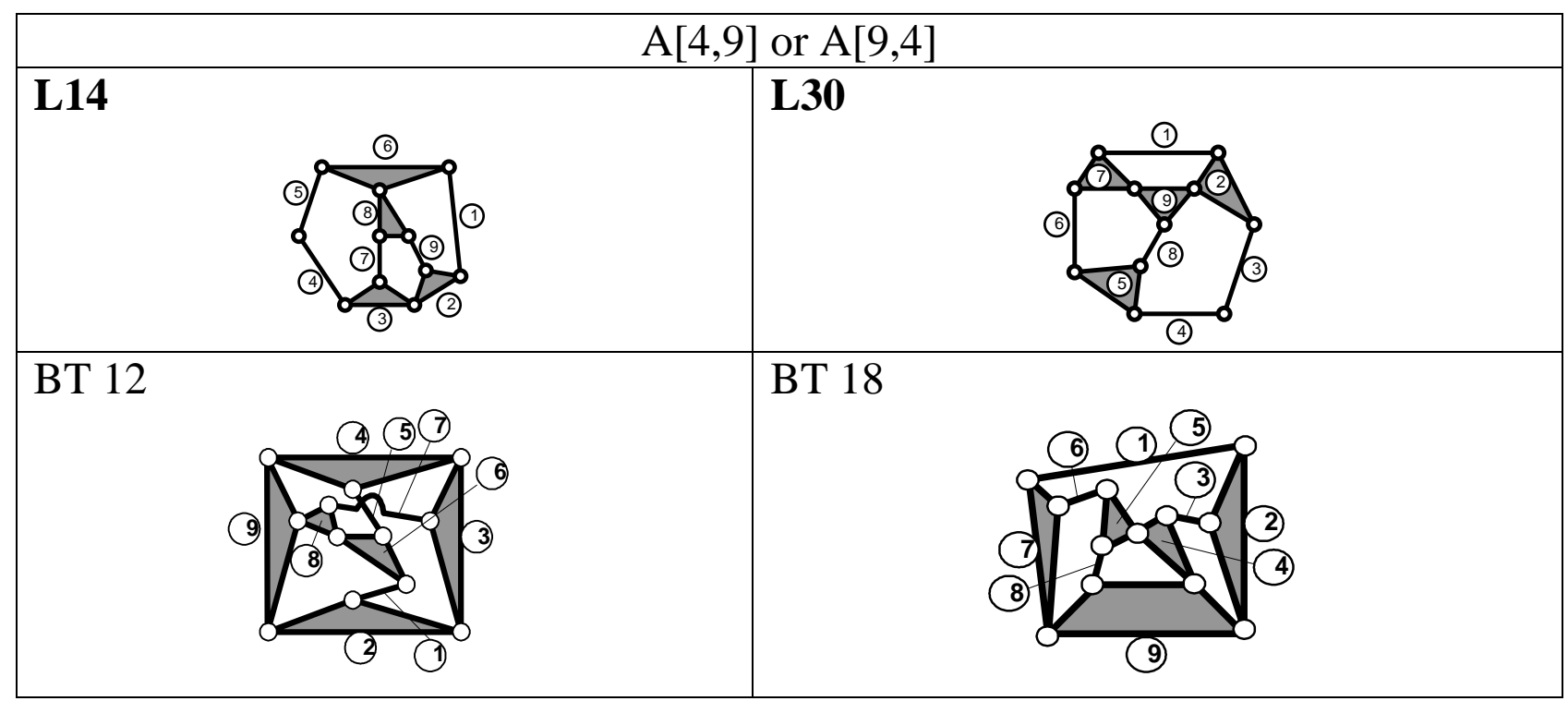

Tab. 20. Solutions for the 4 or 9 basis and the 9 or 4 effector

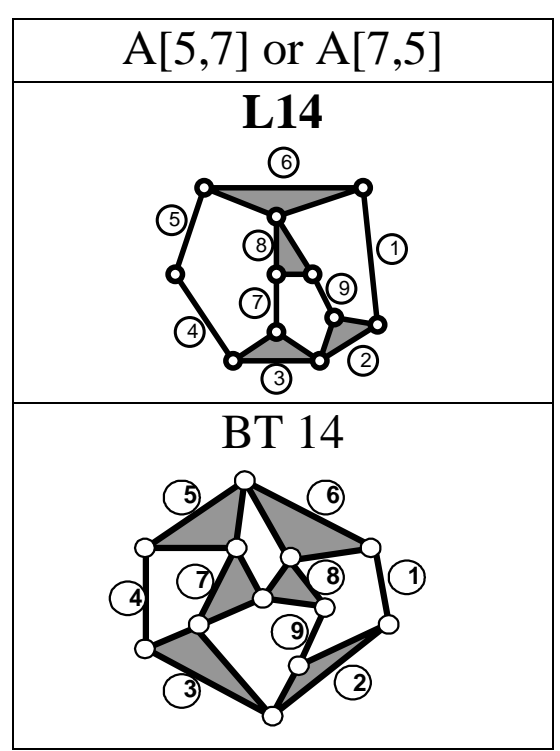

Tab. 21. Solutions for the 5 or 7 basis and the 7 or 5 effector

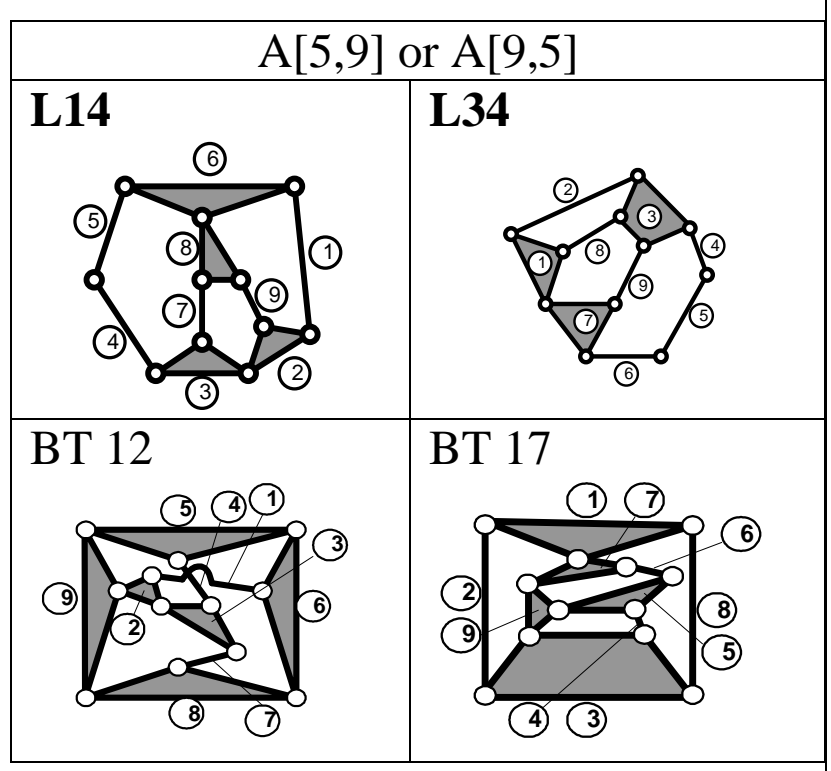

Tab. 22. Solutions for the 5 or 9 basis and the 9 or 5 effector 


(a)

Tab. 23. Solutions for the 6 or 7 basis and the 7 or 6 effector

Having in view the results presented in Tables 3-23 there are found for all linkages (Tab. 1) with three independent loops and two degrees of mobility a total number of 165 solutions for which their inverse models are optimal being a single passive group with eight links.

\section{Optimal structural design of a bi-mobile pedipulator}

At the beginning of this chapter there are mentioned the steps necessary to design a bi-mobile system [Comanescu et al., 2013].

The basis and the effector must satisfy the following requirements [Comanescu et al., 2010]:

- the effector must have a planar motion depending on two independent parameters;

- the effector can not be adjacent to the basis;

- the basis and the effector can not belong to the same four bars linkage, Watt linkage or Stephenson linkage.

For an example, in order to design a new pedipulator from the Table 1 the L33 linkage is selected.

Having in view the previous circumstances the basis-effector matrix is defined.

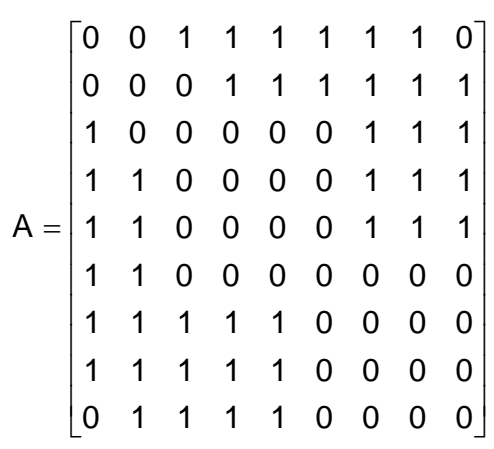


The L33 linkage (Fig. 1) has two mono-mobile structures respectively the $3,4,5,6$ links and the $6,7,8,9$ links and the following symmetrical links $4 \equiv 5 \equiv 8 \equiv 7,3 \equiv 9$ and $1 \equiv 2 . A[i, j]$ has the $i$ basis and the $j$ effector and there are consequently obtained the following 12 distinct solutions:

$$
\begin{array}{rrr}
\mathrm{A}(1,3) & \equiv \mathrm{A}(2,9) & \mathrm{A}(3,1) \equiv \mathrm{A}(9,2) \\
\mathrm{A}(1,4) \equiv \mathrm{A}(1,5) \equiv \mathrm{A}(2,7) \equiv \mathrm{A}(2,8) & \mathrm{A}(4,1) \equiv \mathrm{A}(5,1) \equiv \mathrm{A}(7,2) \equiv \mathrm{A}(8,2) \\
\mathrm{A}(1,6) \equiv \mathrm{A}(2,6) & \mathrm{A}(6,1) \equiv \mathrm{A}(6,2) \\
\mathrm{A}(1,7) \equiv \mathrm{A}(1,8) \equiv \mathrm{A}(2,4) \equiv \mathrm{A}(2,5) & \mathrm{A}(7,1) \equiv \mathrm{A}(8,1) \equiv \mathrm{A}(4,2) \equiv \mathrm{A}(5,2) \\
\mathrm{A}(3,7) \equiv \mathrm{A}(3,8) \equiv \mathrm{A}(9,4) \equiv \mathrm{A}(9,5) & \mathrm{A}(7,3) \equiv \mathrm{A}(8,3) \equiv \mathrm{A}(4,9) \equiv \mathrm{A}(5,9) \\
\mathrm{A}(3,9) \equiv \mathrm{A}(9,3) & \\
\mathrm{A}(4,7) \equiv \mathrm{A}(4,8) \equiv \mathrm{A}(7,4) \equiv \mathrm{A}(8,4) \equiv \mathrm{A}(5,7) \equiv \mathrm{A}(5,8) \equiv \mathrm{A}(7,5) \equiv \mathrm{A}(8,5)
\end{array}
$$

From the Tab. 3 one may find the optimal inverse models for the 1 or 4 link as a basis and respectively the 4 or 1 link as an effector (Fig. 2, Fig.3).

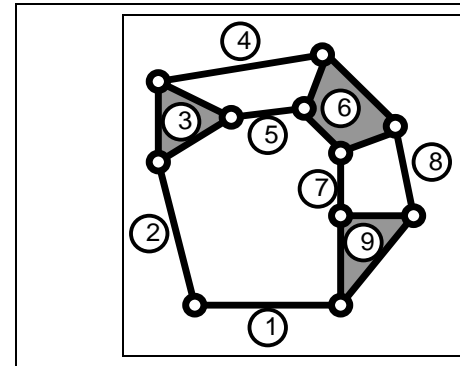

Fig.1. The L33 linkage from the Tab. 1
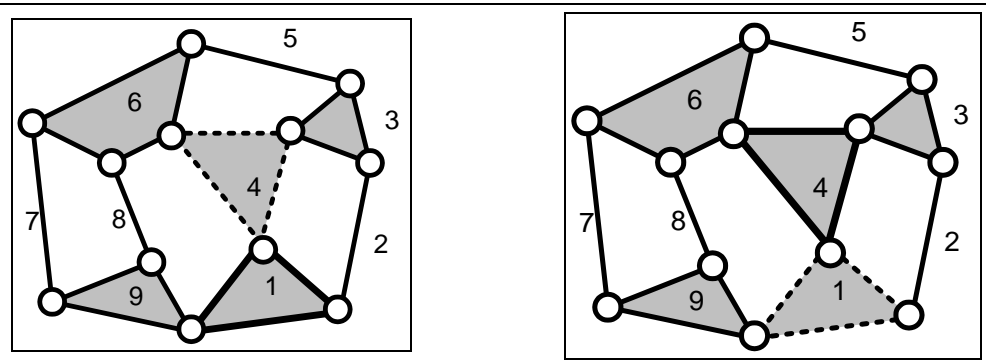

Fig.2. The inverse model Fig.3. The inverse model with the 1 basis and the 4 with the 4 basis and the 1 effector effector

Both inverse models correspond to the BT 17 Baranov truss mentioned in the Tab. 1.

Each inverse model is analyzed in the next figures.

If one adopts the basis 1 and the effector 4 (Fig. 4) it is identified from Tab. 2 the BT 17 truss (Fig. 5) from which by eliminating the 1 link a new passive group with 8 elements is obtained (Fig. 6).

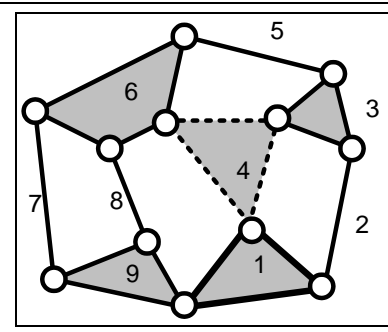

Fig. 4. The inverse model for the 1 basis and the 4 effector

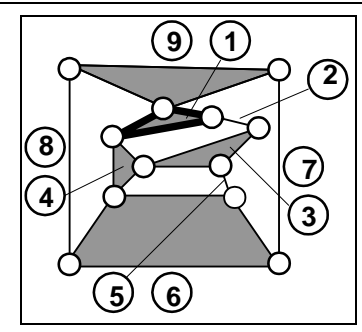

Fig. 5. The BT 17 truss from Table 2

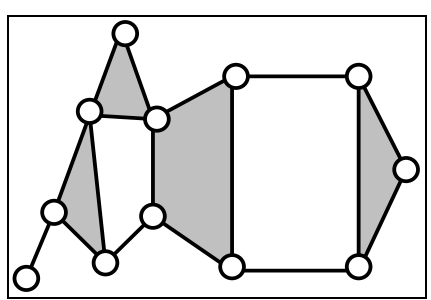

Fig. 6. The new passive group with 8 elements 
Similarly if the 4 basis and the 1 effector are adopted (Fig. 7) the BT 17 truss from Tab. 2 is identified (Fig. 8) and another new passive group with 8 elements (Fig.9).

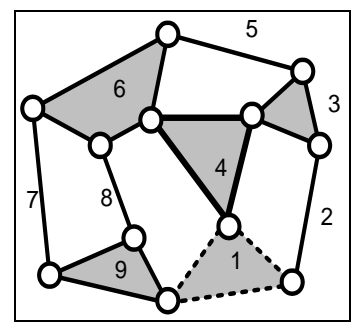

Fig. 7. The inverse model for the 4 basis and the 1 effector

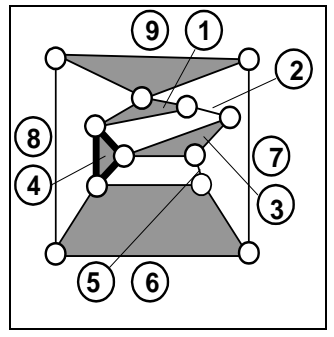

Fig. 8. The BT 17 truss from Tab. 2

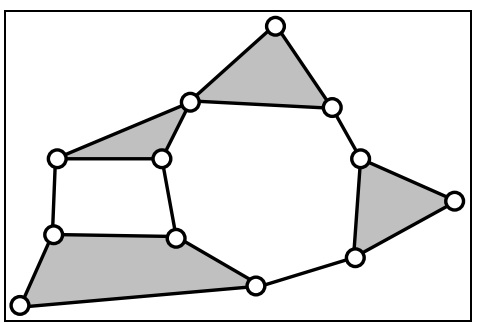

Fig. 9. The new passive group with 8 elements

When the solution with the 4 basis and the 1 effector is adopted the pedipulator (the robot leg) is achieved (Fig. 10) in an adequated software.
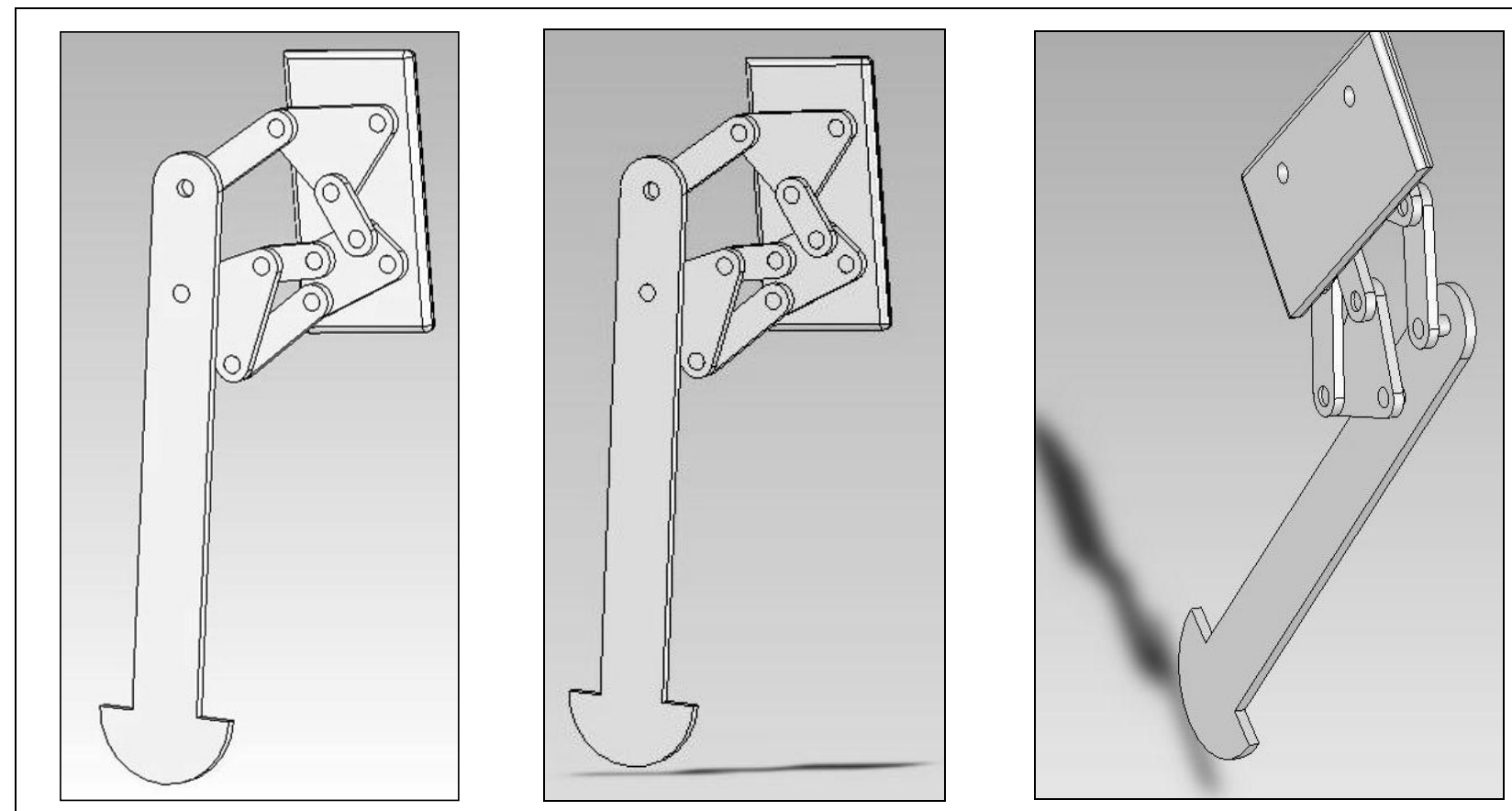

Fig.10. The pedipulator designed by using the inverse model structure

\section{Conclusion}

The paper is relevant in the following aspects:

- a general and unitary method for the structural design of the planar bi-mobile mechanisms especially applied in robotics is elaborated;

- the determination of the optimal structure based on the inverse models for this class of mechanisms firstly presented in the speciality literature.

After some years of applied research there are selected 165 new optimal structural solutions for bi-mobile planar mechanisms. 
Any qualified person may design or verify a new solution for a bi mobile mechanism nevertheless its destination by selecting the linkages from the Table 1 and by choosing the basis and the effector for Tables 3-23, where the respective linkage is found. In this manner it is not necessary to know the theoretical approaches.

The References include the classical titles from the literature dedicated to the Theory of Mechanisms, which are the basis of design for the systems with one degree of mobility. New equipments many of them belonging to robotics are multi-mobile ones and new theoretical methods and techniques are necessary for their optimal design. The research results presented in this chapter fulfil this demand as to the optimal structure of bi mobile mechanisms.

Due to the rich graphical illustration in the next future all these solutions will be included in a date base useful to researchers and designers and to appreciate the patents.

\section{References}

Angeles, J. (2003). Fundamentals of Robotic Mechanical Systems: Theory, Methods and Algorithms, Springer-Verlag New York

Artobolevski, I.I., (1977). Théorie des mécanismes et des machines, Izd.Mir, Moscova

Comănescu, Adr., Comănescu, D. \& Dugăeșescu, I. (2010). Bazele modelării mecanismelor, Editura Politehnica Press, Bucureşti, (Basics of Mechanisms Modeling, Politehnica Publishing Press, Bucharest)

Comănescu, Adr.; Comănescu, D., Dugăeşescu, I. \& Ungureanu, L. (2013). Optimal Inverse Models for Bi-Mobile Mechanisms of Walking Robot Legs, DAAAM International Scientific Book 2013, pp.417-430, B. Katalinic \& Z. Tekic (Eds.), Publisher DAAAM International Vienna, 2013, Vol. 12, ISSN 1726-9687, ISBN 9783-901509-94-0, Vienna

Crossley, F.R.E. (1968). Structural Synthesis of a Four Bit Binary Adding Mechanisms, 10-th ASME Mechanisms Conference, Paper no.68 MECH 25 Atlanta 6-9 Oct.1968

Kakudou, T., Watanabe, K. \& Nagai, I. (2013). Study on Mobile Mechanism of a Climbing Robot for Stair Cleaning: a Translational Locomotion Mechanism and Turning Motion, Journal Artificial Life and Robotics, vol.17, issue 3-4, SpringerVerlag New York

Manolescu, N.; Kovacs, Fr., \& Orănescu, A. (1972). Teoria mecanismelor şi a maşinilor, Editura Didactica si Pedagogica, Bucureşti, (Theory of Mechanisms and Machines, Didactic and Pedagogic Publishing House, Bucharest)

Pelecudi, Chr. (1967). Bazele analizei mecanismelor, Editura Academiei Române, Bucharest, (Basis of Mechanisms Analysis, Romanian Academy Publishing House, Bucharest)

Voinea, R. \& Stroe, I. (2000). Mechanical Structures Dynamics, Editura Academiei Române, Bucureşti, (Romanian Academy Publishing House, Bucharest) 